NBER WORKING PAPER SERIES

\title{
THE EFFECT OF VIETNAM-ERA CONSCRIPTION AND GENETIC POTENTIAL FOR EDUCATIONAL ATTAINMENT ON SCHOOLING OUTCOMES
}

\author{
Lauren L. Schmitz \\ Dalton Conley \\ Working Paper 22393 \\ http://www.nber.org/papers/w22393 \\ NATIONAL BUREAU OF ECONOMIC RESEARCH \\ 1050 Massachusetts Avenue \\ Cambridge, MA 02138 \\ July 2016
}

We thank Aysu Okbay for constructing and sharing the polygenic score for HRS respondents that utilizes weights from the GWAS meta-analysis with the restricted 23andMe and UK Biobank samples. This study was funded by the Russell Sage Foundation (grant number 83-15-29) and by an NIA training grant to the Population Studies Center at the University of Michigan (T32 AG000221). The Health and Retirement Study (HRS accession number 0925-0670) is sponsored by the National Institute on Aging (grant numbers NIA U01AG009740, RC2AG036495, and RC4AG039029) and is conducted by the University of Michigan. Additional funding support for genotyping and analysis were provided by NIH/NICHD R01 HD060726. The views expressed herein are those of the authors and do not necessarily reflect the views of the National Bureau of Economic Research.

NBER working papers are circulated for discussion and comment purposes. They have not been peer-reviewed or been subject to the review by the NBER Board of Directors that accompanies official NBER publications.

(C) 2016 by Lauren L. Schmitz and Dalton Conley. All rights reserved. Short sections of text, not to exceed two paragraphs, may be quoted without explicit permission provided that full credit, including $(\odot)$ notice, is given to the source. 
The Effect of Vietnam-Era Conscription and Genetic Potential for Educational Attainment on Schooling Outcomes

Lauren L. Schmitz and Dalton Conley

NBER Working Paper No. 22393

July 2016

JEL No. I20,I24,I26,J01

\begin{abstract}
This study examines whether draft-lottery estimates of the causal effect of Vietnam-era military service on schooling vary by genetic propensity toward educational attainment. To capture the complex genetic architecture that underlies the bio-developmental pathways behavioral traits and evoked environments associated with educational attainment, we construct a polygenic score (PGS) for the Vietnam-era cohort in the Health and Retirement Study (HRS) that aggregates thousands of individual loci across the human genome, weighted by effect sizes derived from a recent genome-wide association study (GWAS) for years of education. Our findings suggest veterans with below average PGSs for educational attainment completed fewer years of schooling than comparable non-veterans with the same PGS, primarily due to fewer years of college education. On the other hand, we do not find any difference in the educational attainment of veterans and non-veterans with above average PGSs. Results show that public policies and exogenous environments may induce heterogeneous treatment effects by genetic disposition.
\end{abstract}

\author{
Lauren L. Schmitz \\ Population Studies Center \\ University of Michigan \\ 426 Thompson St. \\ Ann Arbor, MI 48104 \\ lschmitz@umich.edu \\ Dalton Conley \\ Department of Sociology \\ Princeton University \\ 153 Wallace Hall \\ Princeton, NJ 08544 \\ and NBER \\ dconley@princeton.edu
}




\section{Introduction}

The Vietnam-era draft was a pivotal moment in the lives of thousands of young men who were called to service. Whether they were deployed to Vietnam or served outside the theater of war, past work has suggested the existence of the draft had a profound impact on the subsequent lives of a generation of men. As Vietnam-era veterans enter their sixties, attention has turned to identifying the lingering effects of military service on the well-being of those who were directly affected. While several studies have used the draft lotteries to evaluate the causal impact of military service on a variety of physical and socioeconomic outcomes, this study is the first to examine whether the educational attainment of conscripts was moderated by genetic influences.

To capture the complex genetic architecture that underlies the bio-developmental pathways, behavioral traits and evoked environments associated with educational attainment, we incorporate the latest approaches from population genetics into a quasi-natural experimental framework to properly identify the independent and joint effects of compulsory military service and genotype on educational outcomes. Specifically, we interact a polygenic score (PGS) for educational attainment with instrumented veteran status in an instrumental variables (IV) framework using data from the Health and Retirement Study (HRS). Our genotype measure exploits findings from a recent large-scale genome-wide association study (GWAS) of educational attainment to construct a PGS scalar that predicts over 14 percent of the variation in years of schooling in our analytic sample (Okbay et al., 2016). Until recently, research on whether genotype-by-environment $(\mathrm{G} \times \mathrm{E})$ interactions shape an individual's educational path has been hindered by the availability of a measure that could capture the multi-faceted and complex genetic architecture of educational attainment. The addition of a comprehensive genetic measure for educational attainment into the analysis provides a window into 
understanding how environmental risks can have lasting effects on the realization of underlying genetic potential.

Importantly, in this study we use an exogenous source of environmental variation in military service - the Vietnam-era draft lotteries - to test for $\mathrm{G} \times \mathrm{E}$ interactions between our PGS for educational attainment and military service. The vast majority of $\mathrm{G} \times \mathrm{E}$ studies in the social, behavioral, and epidemiological sciences are often unable to support causal inference because researchers use endogenous measures of environmental risk or fail to adequately address population stratification-i.e. the nonrandom distribution of genes across environments due to ancestral linkages — confounding estimates (Conley, 2009; Fletcher \& Conley, 2013; Schmitz \& Conley, 2015). In particular, since selection into the military is far from random, and likely to be correlated with factors like socioeconomic background or prior health status, it would be impossible to sort out the effects of military service from other underlying environmental or genetic effects in a model that uses self-reports of veteran status. By exploiting natural variation in exposure to military service together with a comprehensive measure of genotype and controls for population stratification, this study is better equipped to inform policy recommendations that seek to address the emergence and development of social inequality over the life course.

Our findings suggest conscription reduced the educational attainment of veterans with below average PGSs. Veterans with a PGS one to two standard deviations below the mean completed approximately three fewer years of schooling and were 70.7 to 90.6 percent less likely to obtain a postsecondary degree than non-veterans with similar PGSs. On the other hand, we do not find any difference in the educational attainment of veterans and non-veterans with above average PGSs, perhaps because these veterans were more likely to take advantage of generous GI Bill benefits that were available to returning servicemen in the 1970s. Of note, similar to 
prior draft lottery studies that were unable to uncover any lasting evidence of earnings penalties or reductions in employment from conscription (e.g. Angrist, 1990; Angrist \& Chen, 2011; Angrist, Chen, \& Frandsen, 2010; Angrist, Chen, \& Song, 2011), we do not detect any heterogeneous treatment effects by genotype on the labor market outcomes (i.e. earnings, wages, and employment status) of Vietnam-era veterans in their fifties. Therefore, in this study we focus exclusively on disparities in schooling outcomes. ${ }^{3}$

The remainder of the study is outlined as follows. After reviewing the relevant literature on the genetics of educational achievement and the socioeconomic consequences of military service in Section II, we present an in-depth explanation of the data, construction of the PGS, and the empirical model in Section III. Finally, Section IV gives a detailed explanation of our results, and Section V concludes.

\section{Background}

\section{II.A. The Genetics of Educational Attainment}

Twin and family studies have linked a range of behavioral, social, and economic outcomes to genetic differences (Beauchamp et al., 2011; Benjamin et al., 2012; Cesarini et al., 2009). Recent studies suggest the heritability of educational attainment — or the proportion of observed differences in education that can be attributed to genetic differences in a particular population—ranges from around 25 to 40 percent (Branigan, McCallum, \& Freese, 2013; Lucchini, Della Bella, \& Pisati, 2013; Nielsen \& Roos, 2011). The variation in realized phenotypic or observed outcomes between populations that can be ascribed to genetic differences

\footnotetext{
${ }^{3} \mathrm{G} \times \mathrm{E}$ results of conscription and education genotype on earnings, wages, and employment are available from the authors upon request.
} 
is in large part regulated by environmental influences or $\mathrm{G} \times \mathrm{E}$ interactions. However, without a direct measure of genotype, extant research cannot assess the degree to which social and genetic inheritances mediate or moderate each other's influence (Conley et al., 2015).

Finding adequate measures for endowment at conception or birth has long been of interest to social scientists that recognized innate, unmeasured biological variation could be biasing models that seek to isolate the causal effect of schooling on human capital development (for a review see Card, 1999; Card, 1995). However, pinpointing an exact measure has proven difficult because educational attainment is a complex behavioral trait that is moderately correlated with a host of heritable characteristics, including cognitive function (Deary et al. 2007), and personality traits such as persistence and self-discipline (Heckman \& Rubinstein, 2001). Discussions of "ability bias" in the estimated return to education literature have focused primarily on cognitive ability and have used measures of IQ or scores on other cognitive tests like the Armed Forces Qualifying Test (AFQT) to proxy missing ability (Blackburn \& Neumark, 1993; Griliches \& Mason, 1972). Similarly, finding a single measure for non-cognitive skills has proven difficult if not impossible given the diversity of traits like personality or self-esteem that predict educational attainment. In addition, both cognitive and non-cognitive measures are affected by the social environment, which calls into question the pretreatment character of these assessments at any point in time.

To circumvent endogeneity issues, studies have used twin or family models, or measures of family background as controls or instruments (for an overview see Griliches, 1979). However, without a direct measure of genotype, it is often unclear what these measures are capturing. For example, twin and adoptee family studies on socioeconomic success cannot rule out the possibility that presumed genetic differences between biological and adopted children are 
actually proxying unmeasured environmental influences like the birth mother's uterine environment, which has been shown to exert a strong influence on life chances (Almond, Chay, \& Lee, 2005; Almond \& Mazumder, 2011; Black, Devereux, \& Salvanes, 2007; Conley \& Bennett, 2000).

Recently, large-scale genome-wide association studies (GWASs) of educational attainment have identified 74 genome-wide significant loci $\left(p<5 \times 10^{-8}\right)$, or single nucleotide polymorphisms (SNPs), associated with number of years of schooling completed (Okbay et al., 2016; Rietveld et al., 2013). The GWAS findings implicated SNPs in regions that regulate brainspecific gene expression in neural tissue or genotype-tissue expression in the central nervous system (Okbay et al. 2016, p. 540). In addition, results implicate candidate genes and biological pathways that are active during distinct stages of prenatal development. Taken together, the linear polygenic score or joint predictive power of all SNPs from the most recent GWAS explains approximately 3.2 percent of the variation in years of schooling across all participating cohorts in the GWAS meta-analysis (p. 541). These studies have opened up new opportunities for researchers who seek to measure latent biological traits that may be biasing traditional models of socioeconomic attainment.

It is important that a PGS for educational attainment not be misinterpreted as "the gene for ability." If anything, the small amount of variation in educational attainment predicted by the PGS emphasizes the importance of environmental intervention. For example, a meta-analysis of twin studies found that genetic influences on educational attainment diverge considerably across countries and birth cohorts (Branigan et al., 2013). With this in mind, using a PGS for educational attainment has several attractive features for the detection and estimation of $\mathrm{G} \times \mathrm{E}$ relationships. First, complex behavioral outcomes or behaviors of interest to social scientists like 
educational attainment are usually highly polygenic, or reflect the influence or aggregate effect of many different genes (Visscher, Hill, \& Wray, 2008). Second, individual genetic loci influencing the etiology of complex phenotypes have low penetrance; no single gene produces a symptom or trait at a detectable level, making it difficult to distinguish between environmental and genetic factors (Ibid.). Thus, interacting a PGS for educational attainment with a plausibly exogenous environmental shock allows us to detect possible $\mathrm{G} \times \mathrm{E}$ interactions where the biological mechanisms are not yet fully understood (Belsky \& Israel, 2014). This is particularly important for the aim of the present study, which seeks to identify whether genetic influences moderated the educational attainment of conscripts nearly 40 years after the Vietnam War.

\section{II.B. Conscription and Post-Service Socioeconomic Attainment}

The effects of compulsory military service on post-service schooling, earnings, and employment have been largely attributed to two central yet countervailing factors in the literature. On the one hand, conscription may act as an implicit tax on the lifetime education and earnings of soldiers who were coerced into service, paid poorly, and lost valuable labor market experience as a result of their time spent in service (Mason, 1970; Oi, 1967). The two or more years spent on active duty in military service may interrupt or impede career progress, and the training and skills acquired in the military may be of little value to civilian employers or may not be easily transferrable to the civilian sector (Wool, 1968). On the other hand, military service may enhance human capital development through its constellation of job training and support services that are available during and after service.

In particular, there has been a large body of literature that has focused on the long-term effects of the World War II, Korean, and Vietnam-era GI Bills, which among other benefits, 
provided cash payments for university or vocational tuition expenses. ${ }^{4}$ Along these lines, studies have found the GI Bill increased the postsecondary educational attainment of World War II (Bound \& Turner, 2002; Lemieux \& Card, 2001), Korean War (Stanley, 2003), and Vietnam War veterans (Angrist, 1993; Angrist \& Chen, 2011) above that of their non-veteran peers. Estimates are surprisingly comparable across studies and indicate benefits from the GI Bill increased college completion by five to six percentage points and years of college by $0.20-0.33$ years. However, these studies are only able to estimate the local average treatment effect (LATE) of the draft on educational attainment, and are therefore unable to observe whether conscription had heterogeneous treatment effects across the genetic distribution. ${ }^{5}$

Conversely, earnings and employment estimates seem to vary considerably across cohorts and over time. Earlier research finds Vietnam-era veterans tended to be worse off than comparable non-veterans and veterans from the WWII and Korean Wars in terms of income, employment, and job prestige (Card, 1983; Rothbart, Sloan, \& Joyce, 1981; Schwartz, 1986). For example, Schwartz (1986) compares the earnings of Vietnam and Korean veterans twelve to sixteen years after their discharge and finds the rate of return per year of education was significantly lower for Vietnam veterans than Korean veterans, who were economically indistinguishable from their non-veteran contemporaries. Similarly, cross-sectional comparisons show WWII veterans had higher earnings than comparable non-veterans (Berger \& Hirsch, 1983;

\footnotetext{
${ }^{4}$ The WWII GI Bill included a $\$ 500$ tuition supplement and a monthly stipend and was similar to Vietnam-era benefits in the 1970s (adjusting for inflation); benefits were almost double the average cost of tuition, room, and board at a four-year public university during this time period (Angrist \& Chen, 2011; Bound \& Turner, 2002).

${ }^{5} \mathrm{We}$ also estimate the main (instrumented) effect of veteran status in our Vietnam sample and find no LATE of veteran status on schooling. Our estimates most likely diverge from past work because of the considerably smaller sample size of draft eligible men in the HRS compared to studies that have used the 2000 Census (i.e. Angrist and Chen 2011), making it difficult to detect a LATE that is small in magnitude. Table is available from the authors upon request.
} 
Rosen \& Taubman, 1982), though this premium disappears and WWII veterans actually appear to have earned less than comparable non-veterans when nonrandom selection into the military is accounted for using instrumental variable methods (Angrist \& Krueger, 1994).

Results from more recent studies that use the Vietnam-era draft lottery as an instrument for veteran status find the large earnings losses in in the 1970s and 1980s disappear and rapidly converge to zero in the 1990s, or when veterans were approximately 50 years of age (Angrist, 1990; Angrist et al., 2011). Using data from the 2000 Census, Angrist and Chen (2011) reconcile these earnings results by combining earnings estimates with estimated GI Bill effects in a Mincer-style wage equation, and confirm that the near-zero wage penalty at older ages is due to both the flattening of the age-earnings profile in middle-age and economic returns to schooling funded by the GI Bill, which appears to have roughly offset any modest earnings losses due to service. However, the authors point out that lifetime earnings losses to Vietnam veterans have still been negative overall; after accounting for GI Bill benefits, they calculate the present value of lost earnings at around 10 percent of total earnings through the year 2000 (Ibid., p. 116). Finally, studies that use the Vietnam-era draft lotteries have not been able to uncover any evidence of lasting changes in employment rates or labor force participation at older ages (Angrist \& Chen, 2011; Angrist et al., 2010). Similar to these studies, we find little evidence that genetic differences moderated the impact of conscription on the labor market outcomes of Vietnam-era veterans. 


\section{Data and Methodology}

\section{III.A. The Health and Retirement Study}

The HRS is a nationally representative, longitudinal panel study of individuals over the age of 50 and their spouses. Launched in 1992, the study was designed to paint a detailed portrait of the labor force participation and health transitions individuals undergo towards the end of their work lives and into retirement; comprehensive information about participants' socioeconomic background, income, assets, employment, and veteran status is collected alongside genetic data. The HRS introduces a new cohort of participants every six years and interviews around 20,000 participants every two years. For the purposes of this study, we link the Genotype Data Version 1 (2006 and 2008 samples) of the HRS genetic data to both the RAND HRS Data files for socio-demographic information and the restricted Respondent Date of Birth Files (1992-2010) to code for draft eligibility. ${ }^{6}$

The majority of men who were draft eligible during the Vietnam Era entered the HRS in 2004 as part of the "Early Baby Boomer" cohort - a nationally representative sample of men and women born between 1948 and 1953. However, to maximize sample size, we also include spouses of female respondents from former cohorts that were born between 1948 and 1952. Since we use findings from a GWAS conducted on individuals of European ancestry to construct our PGS, our sample excludes respondents who report being of Hispanic, African, American Indian, Alaskan Native, Asian, or Pacific Islander ethnic origin (Carlson et al., 2013). Our final analytic sample includes 504 white, non-Hispanic men born between 1948 and 1952 who provided DNA samples in 2006 or 2008.

\footnotetext{
${ }^{6}$ The RAND HRS Data (Version O, 2015) is an easy to use longitudinal data set based on the HRS data. It was developed at RAND with funding from the National Institute on Aging and the Social Security Administration, Santa Monica.
} 


\section{III.B. Draft Eligibility}

Between 1969 and 1972 the U.S. Selective Service held four Vietnam-era draft lotteries. The first lottery, held in December 1969, affected men born between 1944-1950 who were at risk of conscription in 1970, while subsequent draft lotteries held in 1970 and 1971 affected men who were 19 years old only, or who were born in 1951 or 1952, and at risk of conscription in 1971 or 1972, respectively. A final lottery was held in 1972 for men born in 1953, but no draft calls were issued in 1973. For each lottery, individual birthdates (including February $29^{\text {th }}$ ) were placed in a blue capsule, and then independently drawn until each day of the year was paired with a random sequencing number (RSN) between 1 and 366. After needs for manpower were determined, a draft-eligibility ceiling or cutoff was assigned to each lottery. Men with RSNs below the cutoff were considered draft eligible, while men with RSNs above the cutoff were exempt from the draft. Draft eligibility ceilings were pegged at 195, 125, and 95 for the 1969, 1970, and 1971 lotteries, respectively (see Table 1). Based on these eligibility cutoffs, we follow prior studies and code draft eligibility as equal to " 1 " if the respondent's RSN was called in the corresponding draft year and " 0 " otherwise. ${ }^{7}$

Table 1. Draft eligibility numbers by birth cohort and lottery year

\begin{tabular}{lll}
\hline Lottery year & Birth cohort(s) & Eligibility ceiling \\
\hline 1969 & $1944-1950$ & 195 \\
1970 & 1951 & 125 \\
1971 & 1952 & 95 \\
1972 & 1953 & - \\
\hline
\end{tabular}

Source: U.S. Selective Service

\footnotetext{
${ }^{7}$ The results of the Vietnam draft lottery are available at https://www.sss.gov/About/History-AndRecords/lotter1.
} 
Due to the high number of men who volunteered for the military or received educational deferments before the first draft lottery, studies that use the draft lottery as a natural experiment typically exclude men born between 1944 and 1949 since the link between draft eligibility and veteran status is far from deterministic in these earlier birth cohorts (Angrist, 1990). To determine the probability of service by birth cohort, we follow Dobkin and Shabani (2009) and regress veteran status on draft eligibility and a constant with controls for month of birth for the 1948-1949 and 1950-1952 HRS genotyped cohorts. We find that draft eligible men born between 1948 and 1949 were 18.4 percentage points more likely to serve whereas draft eligible veterans born between 1950 and 1952 were 16.4 percentage points more likely to serve. Thus, due to the similarity of the estimates, the analysis includes men of European ancestry born between 1948 and 1952 to maximize the power of the study.

\section{III.C. Schooling Outcomes}

The HRS asks respondents their highest grade of school or year of college completed. If the respondent reports 12 or fewer years of school, they are asked whether they obtained a high school diploma or passed a high school equivalency test (GED). If the respondent reports 13 or more years of school, they are asked whether or not they obtained a college degree, and if so the highest degree obtained. These responses are categorized as "less than bachelors", "bachelors", "masters/MBA", or "other" which includes the MD, JD, and $\mathrm{PhD}$ degrees. If the respondent

reports 13 or more years of education but does not report receiving a college degree, completion of a high school degree is assumed, but the data do not distinguish a high school diploma from a GED. 
Based on these data, we analyze five schooling outcomes, including highest grade of schooling attended ("years of education"), total years of college education ("years of college") and a series of dichotomous variables denoting whether a respondent completed each degree level ("GED/HS degree +", "associate degree +", and "bachelor's degree +"). "Years of education" is a continuous variable that can range from " 0 " for no formal education to " 17 " for post college education. If the respondent reports receiving at least 12 years of education, we subtract 12 from total years of education reported to obtain "years of college".

Degree variables with a "+" sign are cumulative, so that "GED/HS degree +" indicates those with at least a GED/HS degree. We code these as overlapping subpopulations that diminish from lower to higher levels of schooling so that "associate degree +" compares respondents who received at least an associate degree with those who received a GED/HS degree only while the "bachelor's degree +" variable compares those who received at least a bachelor's degree with respondents who received an associate degree only. This allows us to assess the impact of conscription and genotype on degree transitions, as opposed to their impact on college attendance for all persons, which by definition would compare the cumulative impact of these factors over all previous transitions instead of their respective impact on each degree transition (Mare, 1980). In this way, we can observe changes in the marginal effect of genotype and conscription on degree completion at each level of educational attainment.

\section{III.D. Polygenic Score (PGS)}

The linear PGS is calculated for the HRS sample based on results from a GWAS metaanalysis of educational attainment conducted by the Social Science Genetics Association

\footnotetext{
${ }^{8}$ We follow RAND and categorize individuals who report receiving a college degree but "less than bachelors" as receiving an "associate degree."
} 
Consortium (SSGAC) among people of European ancestry (Okbay et al., 2016). The PGS aggregates thousands of single nucleotide polymorphisms (SNPs) across the genome and weights them by the strength of their association using beta weights derived from the GWAS to yield a single scalar of genetic propensity for educational attainment. Or, the PGS is a weighted sum across the number of SNPs $(n)$ of the number of reference alleles $x$ (zero, one, or two) at that SNP multiplied by the effect size for that $\operatorname{SNP}(\beta)$ :

(1) $\quad P G S_{i}=\sum_{j=1}^{n} \beta_{j} x_{i j}$

We incorporate beta weights from the largest GWAS meta-analysis discovery sample to date, which includes genotype data on individuals from both the UK Biobank and 23andMe in addition to individuals from other participating studies in the SSGAC $(N=395,109)$. Since the HRS is part of the GWAS discovery sample, we use weights estimated by the SSGAC that exclude the HRS sample. ${ }^{9}$ HRS Genotype Data Version 1 (2006 and 2008 samples) were used to construct the PGS-i.e. imputed data was not analyzed. ${ }^{10}$ A total of 1,411,964 SNPs in the HRS genetic database overlapped or matched SNPs from the GWAS meta-analysis. All available SNPs were used to construct the PGS using the software LDpred (Vilhjálmsson et al., 2015). ${ }^{11}$ The PGS is standardized to have a mean of zero and a standard deviation of one for the population of white, non-Hispanic males born between 1948 and 1952.

\footnotetext{
${ }^{9}$ The HRS contributed 9,963 individuals to the meta-analysis - i.e. the total meta-analysis discovery sample size with the HRS included is 405,072.

${ }^{10}$ Genotyping was performed on the HRS sample using the Illumina Human Omni-2.5 Quad beadchip (HumanOmni2.5-4v1 array). The median call-rate for the 2006 and 2008 samples is $99.7 \%$.

${ }^{11}$ LDpred uses a Bayesian method to calculate PGSs that estimates posterior mean causal effect sizes from GWAS summary statistics by assuming a prior for the genetic architecture and linkage
} 
To control for confounding from population stratification, or to account for any ethnic or racial differences in genetic structures within populations that could bias estimates, we use principal components. The principal components measure the uncorrelated variation or dimensions of the data, accounting for the non-random distribution of genes across populations that could bias estimates. We calculate the principal components using second-generation PLINK software (Purcell et al., 2007) on the entire sample of genotyped respondents, and include the first four in our regression analysis - a dimensionality that has generally proven adequate in the literature (Price et al., 2006). ${ }^{12}$

Table 2. Main effect of years of education PGS on schooling outcomes, white non-Hispanic males

\begin{tabular}{lccccc}
\hline & $\begin{array}{c}\text { Years of } \\
\text { education }\end{array}$ & $\begin{array}{c}\text { Years of } \\
\text { college }\end{array}$ & $\begin{array}{c}\text { GED/HS } \\
\text { degree }+\end{array}$ & $\begin{array}{c}\text { Associate } \\
\text { degree }+\end{array}$ & $\begin{array}{c}\text { Bachelor's } \\
\text { degree }+\end{array}$ \\
\hline All white males & $0.639^{* * *}$ & $0.478^{* * *}$ & $0.043^{* * *}$ & $0.100^{* * *}$ & $0.045^{* * *}$ \\
$\mathrm{~N}$ & $(0.045)$ & $(0.031)$ & $(0.006)$ & $(0.008)$ & $(0.010)$ \\
$\mathrm{R}^{2}$ & 3530 & 3530 & 3530 & 3070 & 1250 \\
& 0.055 & 0.058 & 0.017 & 0.043 & 0.020 \\
Veteran sample & & & & & \\
& $0.845^{* * *}$ & $0.762 * * *$ & $0.022 * *$ & $0.153 * * *$ & $0.095^{* * *}$ \\
$\mathrm{~N}$ & $(0.087)$ & $(0.071)$ & $(0.008)$ & $(0.022)$ & $(0.025)$ \\
$\mathrm{R}^{2}$ & 504 & 504 & 504 & 480 & 233 \\
\hline
\end{tabular}

Each column reports a separate ordinary least squares (OLS) regression of the dependent variable on a constant and the years of education PGS. All regressions control for population stratification in the genotype data. PGS is standardized on the analytic sample. Robust standard errors are in parentheses. $* * \mathrm{p}<0.05, * * * \mathrm{p}<0.01$.

disequilibrium (LD) information from a reference panel. This method has been shown to increase the predictive accuracy of PGSs because it does not discard informative markers that may increase heritability estimates and also accounts for the effects of linked markers that can lead to biased estimates, unlike other methods that use pruning or clumping to deal with LD (Vilhjálmsson et al. 2015). The PGS is constructed in LDpred using an LD window of 180 and fraction of causal SNPs assumed to be 1.

${ }^{12}$ We also ran the analysis with the first 10 principal components and did not find any significant differences in the results. 
The score is predictive of all education phenotypes in base, non-interactive main effect models for both the entire sample of white, non-Hispanic genotyped males and in our sample of white, non-Hispanic men born between 1948 and 1952 (see Table 2). The score explains 5.5 percent of the variation in years of education for all white, non-Hispanic males and 14.2 percent of the variation in the Vietnam sample. The higher explanatory power of the score in the Vietnam cohort could in part be due to higher college completion rates among men with above average PGSs who took advantage of GI Bill services. To explore this further, Table 3 reports results from regressions that test the correlation between the PGS and schooling outcomes in the sample of draft eligible and ineligible men.

Table 3. Main effect of years of education PGS on schooling outcomes by draft eligibility, white nonHispanic males

\begin{tabular}{lccccc}
\hline & $\begin{array}{c}\text { Years of } \\
\text { education }\end{array}$ & $\begin{array}{c}\text { Years of } \\
\text { college }\end{array}$ & $\begin{array}{c}\text { GED/HS } \\
\text { degree }+\end{array}$ & $\begin{array}{c}\text { Associate } \\
\text { degree }+\end{array}$ & $\begin{array}{c}\text { Bachelor's } \\
\text { degree }+\end{array}$ \\
\hline Draft eligible & $0.889^{* * *}$ & $0.796^{* * *}$ & 0.016 & $0.186^{* * *}$ & 0.037 \\
$\mathrm{~N}$ & $(0.144)$ & $(0.105)$ & $(0.016)$ & $(0.031)$ & $(0.038)$ \\
$\mathrm{R}^{2}$ & 219 & 219 & 219 & 209 & 95 \\
& 0.161 & 0.205 & 0.0180 & 0.169 & 0.0337 \\
Draft ineligible & & & & & \\
& $0.801^{* * *}$ & $0.723^{* * *}$ & $0.025^{* * *}$ & $0.123^{* * *}$ & $0.128^{* * *}$ \\
$\mathrm{~N}$ & $(0.108)$ & $(0.098)$ & $(0.0087)$ & $(0.029)$ & $(0.032)$ \\
$\mathrm{R}^{2}$ & 285 & 285 & 285 & 271 & 138 \\
\hline
\end{tabular}

Each column reports a separate ordinary least squares (OLS) regression of the dependent variable on a constant and the years of education PGS. All regressions control for population stratification in the genotype data. PGS is standardized on the analytic sample. Robust standard errors are in parentheses. $* * * \mathrm{p}<0.01$.

The score has more prediction power in the draft eligible sample for years of education and years of college completion; however, it is not correlated with completion of a GED or high school degree in draft eligible men. This makes sense given that the majority of men graduated 
high school before they were exposed to the draft, or when they were at least 19 years of age. In addition, veterans who were scheduled to graduate and left high school prematurely to serve in the war were eligible to receive a GED during service, and since the 1990s, many states have also developed programs to grant high school diplomas to qualifying Vietnam-era veterans (Angrist \& Chen, 2011). In other words, we do not find preliminary evidence of a $\mathrm{G} \times \mathrm{E}$ effect from conscription on high school completion.

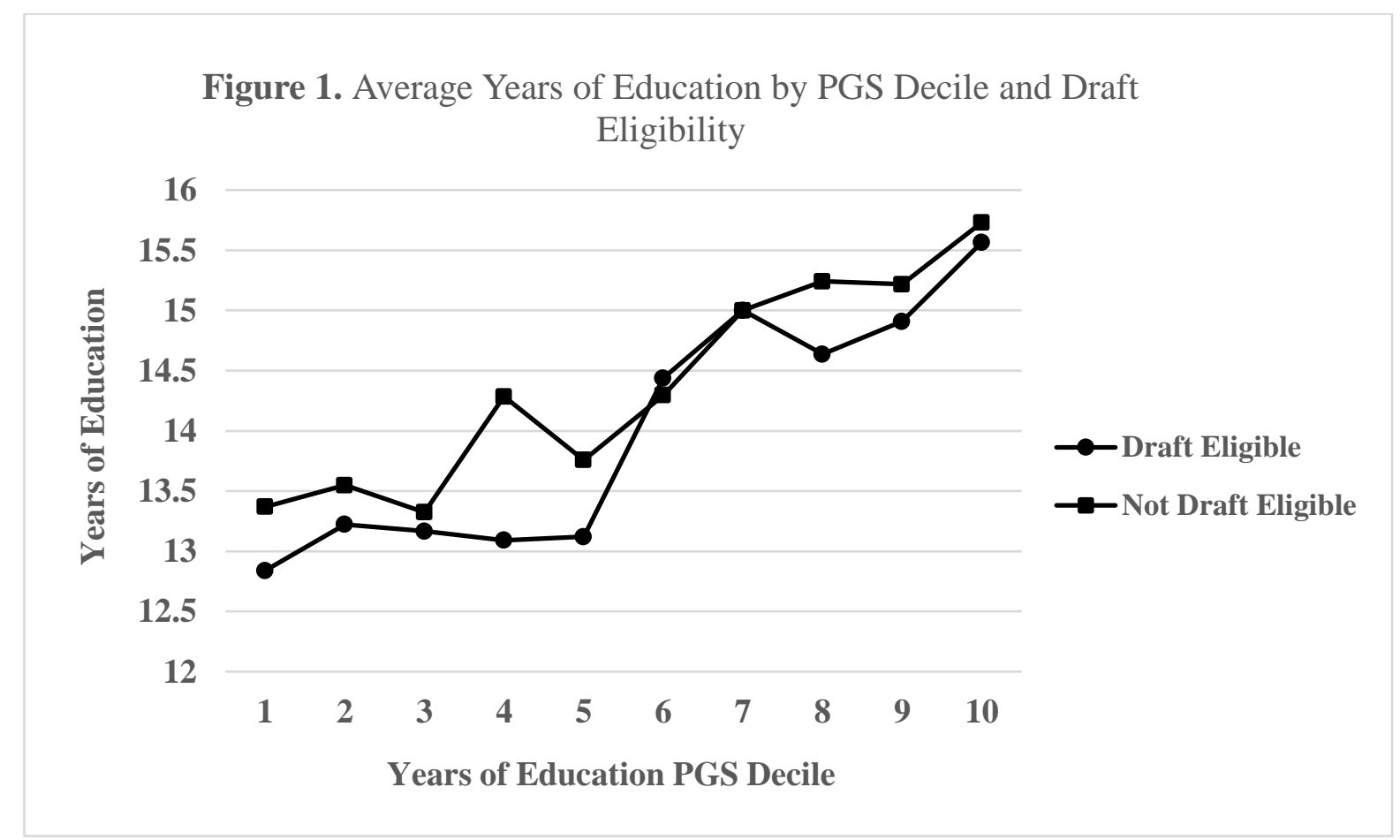

Conversely, the correlation and predictive power of the PGS is higher in the draft eligible sample of men who obtained at least an associate degree, indicating that draft eligible men with higher PGSs were more likely to obtain an associate degree than draft ineligible men. The steeper increase in educational attainment in the top half of the PGS distribution for draft eligible men can be seen in Figure 1, which plots the average years of educational attainment by PGS 
decile and draft eligibility. The figure shows a preliminary (negative) $\mathrm{G} \times \mathrm{E}$ effect in the bottom 50 percent of the PGS distribution, where draft eligible men appear to have obtained fewer years of schooling on average than draft ineligible men. These differences more or less converge in the top half of the distribution, with the exception that draft eligible men in the top 30 percent appear to have obtained slightly fewer years of schooling on average. This could in part explain why the score is not correlated with receiving at least a bachelor's degree in the sample of draft eligible men-i.e. draft eligible men in the top 30 percent of the PGS distribution were less likely to obtain a bachelor's or advanced degree than draft ineligible men.

\section{III.E. Descriptive Statistics}

Veterans are likely to have different educational backgrounds than non-veterans for two primary reasons. First, individuals from higher socioeconomic backgrounds are less likely to enlist in the military because they have more employment and educational opportunities. Second, socioeconomic background aside, individuals with greater potential for educational attainment may be more likely to pursue a postsecondary degree after high school. The first few columns in Table 4 verify these differences. On average, non-veterans completed more years of education (14.5) than veterans (13.7) and more years of college (2.7) than veterans (1.8). Veterans were 18.8 percentage points more likely to have only a high school degree or GED compared to non-veterans, and veterans who attended college were more likely to only obtain an associate degree (0.12) compared to non-veterans (0.05). Completion of a bachelor's degree or advanced degree among non-veterans is nearly double that of veterans; approximately 47.6 percent of non-veterans obtained a bachelor's or advanced degree compared to only 23.6 percent of veterans. Our PGS for educational attainment is also 0.32 standard deviations lower in the 
veteran sample, indicating that veterans with lower PGSs were more likely to select into military service. These observable differences between veterans and non-veterans may lead to biased cross-sectional estimates of the consequences of military service on schooling outcomes if there are other systematic (unobservable) differences between the two groups that we cannot account for.

Table 4. Descriptive statistics by veteran status, 1948-1952 birth cohorts, white non-Hispanic males

\begin{tabular}{|c|c|c|c|c|c|c|c|c|c|}
\hline & All & $\begin{array}{c}\text { Non- } \\
\text { veteran }\end{array}$ & Veteran & Diff. & t stat. & $\begin{array}{l}\text { Not Draft } \\
\text { Eligible }\end{array}$ & $\begin{array}{c}\text { Draft } \\
\text { Eligible }\end{array}$ & Diff. & t stat. \\
\hline Drafted & 0.435 & 0.366 & 0.555 & $-0.188 * * *$ & $(-4.16)$ & 0 & 1 & & \\
\hline Veteran & 0.361 & 0 & 1 & & & 0.284 & 0.461 & $-0.177 * * *$ & $(-4.16)$ \\
\hline Years of education PGS & 0 & 0.114 & -0.202 & $0.315^{* * *}$ & $(3.43)$ & -0.025 & 0.032 & -0.057 & $(-0.63)$ \\
\hline Years of education & 14.188 & 14.478 & 13.676 & $0.802 * * *$ & $(3.86)$ & 14.316 & 14.023 & 0.293 & (1.44) \\
\hline Years of college (0-5) & 2.357 & 2.665 & 1.813 & $0.851 * * *$ & $(4.86)$ & 2.446 & 2.242 & 0.204 & $(1.17)$ \\
\hline \multicolumn{10}{|l|}{ Highest degree completed } \\
\hline No degree & 0.048 & 0.056 & 0.033 & 0.023 & $(1.16)$ & 0.049 & 0.046 & 0.003 & $(0.18)$ \\
\hline High school degree & 0.49 & 0.422 & 0.61 & $-0.188 * * *$ & $(-4.10)$ & 0.467 & 0.521 & -0.054 & $(-1.20)$ \\
\hline Associate degree & 0.073 & 0.047 & 0.121 & $-0.074 * * *$ & $(-3.09)$ & 0.081 & 0.064 & 0.017 & $(0.71)$ \\
\hline Bachelor's degree & 0.236 & 0.28 & 0.159 & $0.120 * * *$ & $(3.07)$ & 0.232 & 0.242 & -0.010 & $(-0.27)$ \\
\hline Advanced degree & 0.153 & 0.196 & 0.077 & $0.119 * * *$ & $(3.60)$ & 0.172 & 0.128 & 0.0441 & $(1.36)$ \\
\hline Ever married & 0.869 & 0.863 & 0.879 & -0.016 & $(-0.50)$ & 0.874 & 0.863 & 0.011 & $(0.35)$ \\
\hline $\mathrm{N}$ & 504 & 322 & 182 & & & 285 & 219 & & \\
\hline
\end{tabular}

In addition, since the HRS is a study of older adults, potential problems could arise if conscripts who survived to be genotyped in 2006 or 2008 were more likely to be educated and therefore have lower mortality rates than comparable populations (Domingue et al., 2016). If increased education is an alternative pathway affecting the military conscription-mortality relationship, draft eligibility is no longer exogenous, and the exclusion restriction on which our 2SLS estimates rest will be violated. Prior studies on selective mortality effects in the draftlottery sample have been mixed. A pioneering study by Hearst, Newman, and Hulley (1986) found excess deaths from suicide and motor vehicle accidents among draft-eligible men from 
California and Pennsylvania. However, more recently, Conley and Heerwig (2012) find no effect of draft exposure on mortality, including for cause-specific death rates, in a larger sample of national death records, and Angrist et al. (2010) find little evidence of elevated mortality among draft-eligible men in the 2000 census. Importantly, Conley and Heerwig (2012) do find some evidence of elevated mortality among draft-eligible, college-educated men. However, they argue this effect works in the opposite direction of putative education-enhancing effects that could potentially violate the exclusion restriction in IV regression models-i.e. high SES men were not more likely to survive.

Crucially, results in the last four columns of Table 4 reveal no significant difference in draft eligible and ineligible means by PGS, schooling outcome, or marital status, suggesting bias from unobserved differences, mortality selection, sample attrition, or genetic screening consent is modest if nonexistent in the draft eligible birth cohorts. In the overall, genotyped, HRS male sample ( $\mathrm{N}=3,530)$, year of birth is highly correlated with the PGS (see also Conley et al., 2016) - perhaps not surprising given the well-documented association between education and longevity (Conti, Heckman, \& Urzua, 2010; Cutler \& Lleras-Muney, 2010; Lleras-Muney, 2005). However, we find that the PGS is not correlated with year of birth in our Vietnam-era analytic sample, indicating that men with above average PGSs were not more likely to survive than men at the bottom half of the PGS distribution. The difference between the overall sample and our analytic sample is probably due to two factors: 1) The Vietnam-draft birth cohorts are still on the younger side of HRS respondents and thus may not have fully evinced educationalPGS associated mortality and 2) The birth year window is quite narrow within our analytic sample. That said, adjusting for mortality bias generally does not affect cohort-PGS results in the HRS even across the entire range of the sample (Domingue et al., 2016). 
Finally, Table 5 compares descriptive statistics for men in our sample who were genotyped $(\mathrm{N}=504)$ with same-age white, non-Hispanic men who were not genotyped $(\mathrm{N}=485)$. Two sample t-tests reveal no significant differences between the means of the two groups with the exception that men who were not genotyped are 3.07 percentage points more likely to not have an academic degree. We also find evidence that genotyped men were more likely to be married while they were in the HRS sample (0.87) than men who were not genotyped (0.83), though this difference is only statistically significant at the $p<.10$ level.

Table 5. Descriptive statistics by genotyped status, 1948-1952 birth cohorts, white non-Hispanic males

\begin{tabular}{lccccc}
\hline & All & $\begin{array}{c}\text { Not } \\
\text { Genotyped }\end{array}$ & Genotyped & Diff. & t stat. \\
\hline Drafted & 0.439 & 0.443 & 0.435 & 0.009 & $(0.28)$ \\
Veteran & 0.355 & 0.348 & 0.361 & -0.013 & $(-0.42)$ \\
& & & & & \\
Years of education & 14.1 & 14.008 & 14.188 & -0.180 & $(-1.21)$ \\
Years of college (0-5) & 2.303 & 2.247 & 2.357 & -0.110 & $(-0.88)$ \\
& & & & & \\
Highest degree completed & & & & & \\
No degree & 0.063 & 0.078 & 0.048 & $0.031^{* *}$ & $(2.00)$ \\
High school degree & 0.496 & 0.503 & 0.49 & 0.013 & $(0.41)$ \\
Associate degree & 0.068 & 0.062 & 0.073 & -0.012 & $(-0.72)$ \\
Bachelor's degree & 0.216 & 0.196 & 0.236 & -0.040 & $(-1.54)$ \\
Advanced degree & 0.157 & 0.161 & 0.153 & 0.008 & $(0.35)$ \\
Ever married & 0.848 & 0.827 & 0.869 & $-0.042^{*}$ & $(-1.85)$ \\
N & 989 & 485 & 504 & & \\
\hline Education PGS is standardized on the analytic sample. ${ }^{*} \mathrm{p}<0.10, * * \mathrm{p}<0.05$. &
\end{tabular}

\section{III.F. Empirical Model}

Following prior studies, we use the Vietnam-era draft lottery as an instrument for veteran status to identify the causal effect of military service and genotype on veterans' schooling. Since past research has shown draft eligibility is 1) highly correlated with actual veteran status, and 2) 
only affects educational outcomes through the first stage channel, or through its correlation with veteran status, it is considered a valid instrument for military service. ${ }^{13}$ Consider the following $\mathrm{G} \times \mathrm{E}$ interaction model:

$$
Y_{i}=\alpha_{1} V E T_{i}+\alpha_{2} P G S_{i} \times V E T_{i}+X_{i}^{\prime} \alpha_{3}+\varepsilon_{i}
$$

Where, $V E T_{i}$ is coded as " 1 " if individual $i$ reports serving in the military and " 0 " otherwise, $P G S_{i}$ is the polygenic score for educational attainment, $P G S_{i} \times V E T_{i}$ is their interaction, $Y_{i}$ is the schooling outcome of interest, $X_{i}$ is a vector of exogenous controls, and $\varepsilon_{i}$ is the disturbance term. The $V E T_{i}$ and $P G S_{i} \times V E T_{i}$ terms are treated as endogenous and the $D_{R A F T_{i}}$ and $P G S_{i} \times D R A F T_{i}$ terms are used as excluded instruments in a two-stage least squares (2SLS) IV framework, where $D R A F T_{i}$ is coded as " 1 " for draft eligible men and "0" for draft ineligible men in accordance with the draft eligibility ceilings reported in Table 1 (Schmitz \& Conley, 2016). The first-stage regressions for the $\mathrm{G} \times \mathrm{E}$ interaction model are as follows:

$$
\begin{aligned}
& V E T_{i}=\pi_{1} D_{R A F T_{i}}+\pi_{2} P G S_{i} \times D R A F T_{i}+X_{i}^{\prime} \pi_{3}+\eta_{i} \\
& P G S_{i} \times V E T_{i}=\gamma_{1} D R A F T_{i}+\gamma_{2} P G S_{i} \times D R A F T_{i}+X_{i}^{\prime} \gamma_{3}+\rho_{i}
\end{aligned}
$$

\footnotetext{
${ }^{13}$ The first condition is easy to verify, and standard first stage statistics (partial $\mathrm{R}^{2}$ and F-statistic) for the significance of the instruments in the HRS sample show draft eligibility is a robust predictor of veteran status (see Table 6). The exclusion restriction, or second condition, cannot directly be tested. Heckman (1997) shows the IV estimator is not consistent if heterogeneous behavioral responses to the treatmentor military service in this case - are correlated with the instrument (i.e. draft eligibility). However, past research has provided convincing counterfactuals that suggest the exclusion restriction holds. For example, Angrist (1990) found no significant relationship between earnings and draft eligibility status for men born in 1953 (where draft eligibility was defined using the 1952 lottery cutoff of 95). Since the 1953 cohort was assigned RSNs but never called to service, if the draft affected outcomes directly, we would expect outcomes to vary by draft eligibility for this cohort.
} 
Where the model is exactly identified - i.e. the number of excluded instruments $\left(D R A F T_{i}\right.$ and $\left.P G S_{i} \times D R A F T_{i}\right)$ are equal to the number of endogenous regressors $\left(V E T_{i}\right.$ and $\left.P G S_{i} \times V E T_{i}\right)$. The vector of exogenous controls $\left(X_{i}\right)$ includes the main effect of the PGS, which we model as $P G S_{i} \times N O D R A F T_{i}$, where NODRAFT $T_{i}$ is equal to "1" if individuals were not drafted and never served in the military, and " 0 " otherwise. We also control for the first four principal components to account for population stratification in the genotype data and dummies for year and month of birth. ${ }^{14}$

Note that in a typical linear regression model with an interaction term, the interaction term and each of the corresponding main effects are modeled as separate terms (i.e. $D R A F T_{i}$, $P G S_{i} \times D R A F T_{i}$ and $\left.P G S_{i}\right)$. Here, we model the main effect of $P G S_{i}$ as $P G S_{i} \times N O D R A F T_{i}$ for two reasons. First, as shown in our descriptive statistics in Table 4, $P G S_{i}$ is an invalid instrument because it is negatively and significantly correlated with veteran status, meaning that men with lower PGSs were more likely to select into the military. This can also be seen in Table 6 below, which contains first stage statistics for models where the main effect is modeled both as $P G S_{i}$ (Column 1) and as $P G S_{i} \times N O D R A F T_{i}$ (Column 2). First stage estimates reveal that when the main effect of $P G S_{i}$ is modeled as $P G S_{i} \times N O D R A F T_{i}$ the correlation between the main effect and veteran status is eliminated-i.e. $P G S_{i}$ is exogenous and no longer correlated with veteran status in the (randomized) draft eligible and ineligible groups. Second, because we are using a 2SLS approach, and $P G S_{i}$ is highly correlated with $P G S_{i} \times D R A F T_{i}$, modeling the main effect of $P G S_{i}$ as $P G S_{i} \times N O D R A F T_{i}$ strengthens the correlation between the $P G S_{i} \times V E T_{i}$ and $P G S_{i} \times$

\footnotetext{
${ }^{14}$ A mechanical failure in the implementation of the first round of the lottery (balls with the days of the year were not mixed sufficiently after having been dumped in a month at a time) resulted in a disproportionately high probability of being drafted for those born in the last few months of the year (Fienberg, 1971). This could bias estimates if those born later in the year differ in important ways from those born at other times during the year. For example, studies have shown health varies with season of birth.
} 
$D R A F T_{i}$ terms, which increases the precision of the first stage estimates and improves the finitesample performance of the 2SLS estimator.

Table 6. Draft-Lottery first stage statistics, 1948-1952 birth cohorts, white non-Hispanic males

\begin{tabular}{|c|c|c|c|c|}
\hline & \multicolumn{2}{|c|}{ (1) } & \multicolumn{2}{|c|}{ (2) } \\
\hline & Veteran & Veteran $\times$ PGS & Veteran & Veteran $\times$ PGS \\
\hline \multirow[t]{2}{*}{ Draft eligibility } & $0.165 * * *$ & $0.087 *$ & $0.162 * * *$ & $0.091^{*}$ \\
\hline & $(0.0457)$ & $(0.0470)$ & $(0.0469)$ & $(0.0503)$ \\
\hline \multirow[t]{2}{*}{ Draft eligibility $\times$ PGS } & 0.041 & $0.155^{* *}$ & -0.049 & $0.411 * * *$ \\
\hline & $(0.0433)$ & $(0.0652)$ & $(0.0331)$ & $(0.0506)$ \\
\hline \multirow[t]{2}{*}{ PGS } & $-0.089 * * *$ & $0.253 * * *$ & & \\
\hline & $(0.0269)$ & $(0.0395)$ & & \\
\hline \multirow[t]{2}{*}{ Not drafted or a veteran $\times$ PGS } & & & -0.024 & 0.026 \\
\hline & & & $(0.0269)$ & $(0.0214)$ \\
\hline $\mathrm{N}$ & 504 & 504 & 504 & 504 \\
\hline Adjusted $\mathrm{R}^{2}$ & 0.103 & 0.385 & 0.085 & 0.279 \\
\hline F-Statistic & 7.459 & 5.637 & 6.922 & 35.61 \\
\hline
\end{tabular}

All regressions control for population stratification in the genotype data and respondent month and year of birth. PGS is standardized on the analytic sample. Robust standard errors are in parentheses. ${ }^{*} \mathrm{p}<0.10, * \mathrm{p}<0.05,{ }^{* * *} \mathrm{p}<0.01$

Finally, we substitute the first stage equations in Table 6, Column 2 into the structural equation to derive the reduced form in the second stage:

(5) $Y_{i}=\delta_{1} D R A F T_{i}+\delta_{2} P G S_{i} \times D R A F T_{i}+X_{i}^{\prime} \delta_{3}+\xi_{i}$

For all limited and continuous dependent variables in this study, the second stage equation is estimated with a simple linear probability model because it is the ideal specification when faced 
with a set of simultaneous equations where the instrument, the endogenous regressor, and the dependent variable take on a limited set of values (Angrist \& Pischke, 2008).

As long as $D R A F T_{i}$ is exogenous and only affects the outcome through the first stage channel, or through its correlation with $V E T_{i}$, we avoid any potential confounders, and the coefficient on $\delta_{1}$ can be interpreted as the local average treatment effect (LATE) of military status, or the difference in schooling outcomes between veterans and non-veterans with an average PGS. ${ }^{15}$ Modeling the main effect of $P G S_{i}$ as $P G S_{i} \times N O D R A F T_{i}$ does not change the meaning of this term, which can still be interpreted as the marginal effect of $P G S_{i}$ on schooling for men who were not drafted and who did not serve. However, it does change the interpretation of $\delta_{2}$, which now represents the marginal effect of $P G S_{i}$ on schooling for draft eligible veterans instead of the expected difference in the marginal effects between draft eligible veterans and draft ineligible non-veterans. Therefore, when we estimate the average treatment effect of veteran status by genotype in the "Results" section, we subtract the treatment effect for nonveterans $\left(P G S_{i} \times N O D R A F T_{i}\right)$ from the treatment effect for veterans $\left(D R A F T_{i}+P G S_{i} \times\right.$ $\left.D R A F T_{i}\right)$ to calculate the expected difference in schooling outcomes between the two groups.

\section{Results}

Our main results are presented in Table 7, which reports the OLS and 2SLS estimates from the $\mathrm{G} \times \mathrm{E}$ interaction model. The OLS estimates are remarkably comparable to the $2 \mathrm{SLS}$ estimates in both magnitude and sign, although the OLS estimates tend to be slightly lower

\footnotetext{
${ }^{15}$ The IV estimates of effects of military service using the draft lottery capture the effect of military service on "compliers", or men who served because they were draft eligible but who would not otherwise have served. It is not, therefore, an estimate of the effect of military service on men who volunteered. See Angrist and Pischke (2008) for a more detailed discussion of the interpretation of the LATE for the Vietnam-era draft.
} 
across the board. This stands in stark contrast to the schooling outcomes reported by Angrist and Chen (2011) in the 2000 Census where OLS estimates diverged considerably from 2SLS estimates and often displayed opposite signs. Therefore, it appears including the PGS in the OLS model may reduce some of the confounding between educational outcomes and nonrandom selection into the military. Nevertheless, we cannot rule out the possibility that the OLS estimates are biased downward due to other unobserved characteristics.

Pivoting to the IV estimates, we report coefficients from the causal 2SLS model in the second column for each schooling outcome in Table 7. 2SLS estimates of "Veteran" capture the effect of conscription on schooling at the mean value of the PGS, and the "PGS $\times$ Veteran" coefficient captures the effect of compulsory military service at all other values of the PGS. The "PGS $\times$ Non-Veteran" coefficient is the effect of the PGS on men who were not treated, or those who were not drafted and who did not serve in the military. In addition, we report the average treatment effect of veteran status, or the total difference in schooling outcomes between veterans and non-veterans, by PGS in Table $8 .{ }^{16}$

Coefficients on the "Veteran $\times$ PGS" and "Non-Veteran $\times$ PGS" interaction terms in Table 7 are significant and indicate higher levels of educational attainment for each standard deviation increase in the PGS. Notably, results for highest degree obtained indicate the absence of a veteran $\mathrm{G} \times \mathrm{E}$ effect for $\mathrm{GED} / \mathrm{HS}$ completion. Again, this is not surprising given the vast majority of veterans - regardless of genotype - were exposed to the draft after they completed high school.

\footnotetext{
${ }^{16}$ The marginal effect of veteran status by genotype is estimated by adding the individual treatment effects for veterans ("Veteran" + "Veteran $\times$ PGS") and subtracting them from the treatment effect for non-veterans who were not drafted ("Non-Veteran" $\times$ "PGS") at a given PGS value. This is done using a post-linear combination to ensure the accuracy of the standard errors.
} 


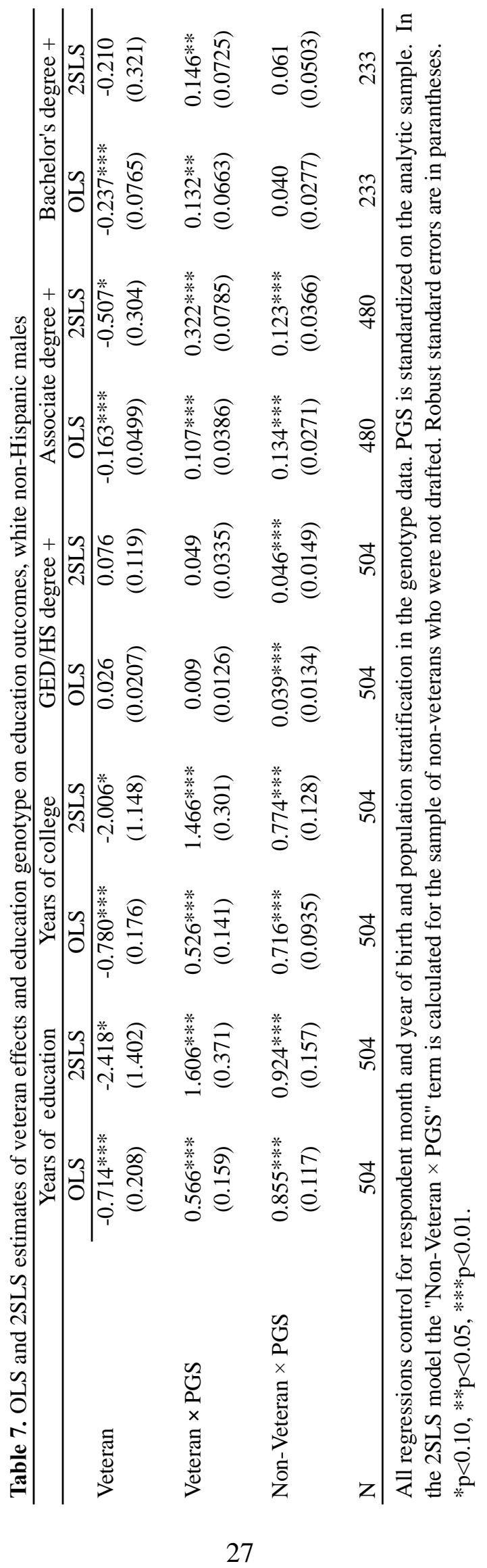


The $\mathrm{G} \times \mathrm{E}$ effect is, however, significantly stronger for veterans who completed at least an associate degree, indicating veterans with above average PGSs were more likely to take advantage of GI Bill benefits and complete additional schooling after the war. However, the effect of the PGS completely disappears for non-veterans and is substantially diminished for veterans in the population of individuals who completed a bachelor's degree. Thus, genetic propensity played a larger role in the completion of an associate degree after the war than in the completion of a bachelor's or advanced degree.

Table 8. Average Treatment Effect of Veteran Status by Genotype

\begin{tabular}{lccccc}
\hline & $\begin{array}{c}\text { Years of } \\
\text { education }\end{array}$ & $\begin{array}{c}\text { Years of } \\
\text { college }\end{array}$ & $\begin{array}{c}\text { GED/HS } \\
\text { degree }+\end{array}$ & $\begin{array}{c}\text { Associate } \\
\text { degree }+\end{array}$ & $\begin{array}{c}\text { Bachelor's } \\
\text { degree }+\end{array}$ \\
\hline PGS=2 & -1.055 & -0.623 & 0.083 & -0.108 & -0.040 \\
& $(1.589)$ & $(1.302)$ & $(0.139)$ & $(0.348)$ & $(0.282)$ \\
PGS=1 & -1.736 & -1.314 & 0.0792 & -0.308 & -0.125 \\
& $(1.446)$ & $(1.185)$ & $(0.125)$ & $(0.315)$ & $(0.289)$ \\
PGS=-1 & $-3.100 * *$ & $-2.698 *$ & 0.072 & $-0.707 * *$ & -0.295 \\
& $(1.464)$ & $(1.200)$ & $(0.122)$ & $(0.315)$ & $(0.373)$ \\
PGS=-2 & & & & & -0.380 \\
& $-3.782 *$ & $-3.390 * *$ & 0.069 & $-0.906 * *$ & $-0.348)$ \\
$\mathrm{N}$ & $(1.621)$ & $(1.331)$ & $(0.134)$ & $(0.348)$ & $(0.438)$ \\
\hline
\end{tabular}

The average treatment effect for veterans is estimated by adding the total marginal effect for veterans in Table VII ("Veteran" + "Veteran × PGS") and subtracting it from the marginal effect for nonveterans ("Non-Veteran $\times$ PGS") for each of the above PGS values. To ensure the accuracy of the standard errors, this is done using a post-estimation linear combination. Robust standard errors are in parentheses. **p<0 $05, * * * \mathrm{p}<0.01$

Overall, we do not find any evidence that compulsory military service and subsequent access to GI Bill benefits increased the educational attainment of veterans above that of non- 
veterans. Results reported in Table 8 show no difference in schooling outcomes between veterans and non-veterans with above average PGSs, or those with a PGS one to two standard deviations above the mean. In other words, veterans with above average PGSs reached similar levels of schooling as their same-PGS non-veteran counterparts. Conversely, we find military service reduced the educational attainment of veterans with below average PGSs. Model estimates show conscripts with a PGS one standard deviation below the mean obtained 3.1 fewer years of education and attended 2.7 fewer years of college than non-veterans with similar PGSs. These veterans were also 70.7 to 90.6 percent less likely to obtain an associate, bachelor's, or advanced degree $(\mathrm{PhD}, \mathrm{JD}$, or $\mathrm{MD})$.

\section{Figure 2. Difference in Predicted Years of Education: \\ Veterans versus Non-Veterans}

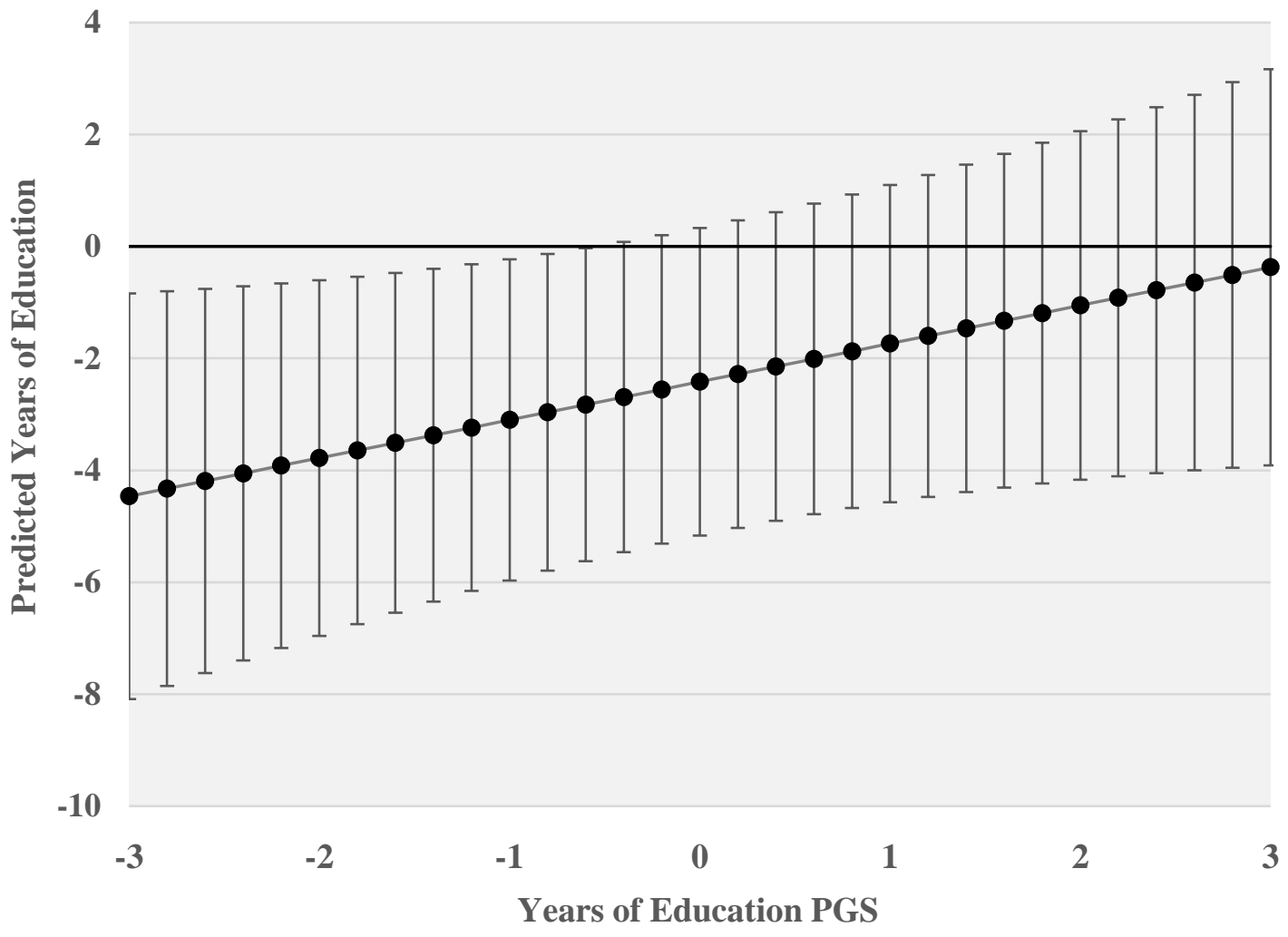


The sizable variation in schooling by PGS can also be seen in Figure 2 above, which plots the difference in years of schooling between veterans and non-veterans at all values of the PGS with 95\% confidence intervals. A treatment effect persists for veterans with a PGS at or below -0.6 , whereas the treatment effect at higher values of the PGS is not significant. ${ }^{17}$

\section{Discussion}

Surviving Vietnam-era veterans are currently the single largest veteran population in the United States. Over 7.2 million Vietnam veterans constitute 32.9 percent of the total veteran population and receive the largest overall share and per veteran share of service-related disability benefits (NCVAS, 2015) - a figure that is growing as the population ages. The annual compensation to veterans from the Vietnam Era more than doubled between 2003 and 2012, reaching $\$ 19.7$ billion of the total paid to veterans that year of $\$ 44.4$ billion (Ibid.). Given the well-established relationship between investments in human capital and improved health, employment opportunities, and income across the life span, a deeper understanding of whether biological and social forces shape the educational outcomes of veterans is needed.

Contrary to the small gains in schooling found by Angrist and Chen (2011), in this study we do not find any evidence that conscription increased the schooling of Vietnam-era veterans in our HRS sample. Conflicting estimates are likely the byproduct of differences in power and sample population between the 2000 Census and the HRS. However, despite a significantly lower sample size, we find evidence that draft exposure reduced the educational attainment of conscripts with below average PGSs for educational attainment. Draft eligible men with below average PGSs completed approximately three fewer years of schooling and were approximately

\footnotetext{
${ }^{17}$ We note that due to low sample sizes at higher and lower values of the PGS, IV estimates more than two standard deviations away from the mean may not accurately predict the treatment effect.
} 
70.7 to 90.6 percent less likely to obtain a postsecondary degree. On the other hand, we find no difference in schooling outcomes between veterans and non-veterans with above average PGSs. Taken together, this suggests that high-PGS veterans were more likely to take advantage of generous GI Bill benefits, which paid more than double the average cost of tuition, room, and board at a four-year public university in the 1970s.

A significant drawback of our IV estimation strategy is we cannot fully describe the underlying theoretical relationships between military service and educational attainment that may be driving our results. For example, we cannot disentangle the particular aspects of military service in Vietnam—such as combat positions, year of service, or number of tours- that may be linked to post-traumatic stress or other debilitating conditions that limited the long-term socioeconomic attainment of veterans. In particular, assignment to the theater of war was by no means random and studies have shown that men with lower Armed Forces Qualification Test (AFQT) scores and fewer support role skills were more likely to be exposed to combat (e.g. Gimbel \& Booth, 1996). The data reported here are entirely consistent with higher IQ conscripts holding safer non-combat or administrative support positions and taking disproportionate advantage of the GI Bill after service. In other words, our IV model does not explain why Vietnam-era service negatively affected the educational attainment of veterans with below average PGSs.

However, despite weaker claims to external validity, the model's high degree of internal validity may direct practitioners to effective treatments that could increase the educational attainment, enhancement of skills, and overall assimilation into civilian life of returning veterans. Although we caution that the estimates from our study apply specifically to Vietnam-era veterans, and thus cannot be generalized to the population as a whole or even to current military 
personnel, to the extent that the Vietnam-era draft lottery serves as a proxy for stressful events in young adulthood, or exposure to combat, policymakers may want to design interventions that minimize the negative impact of similar traumatic events on scholastic achievement. Similarly, in terms of future research, while we do discover some heterogeneity in treatment effects from military service on schooling by genotype, more research is needed to identify how genetic attributes modify the effect of military service on earnings and employment in mid-life. In particular, studies that can track veterans across the entire life course would lend insight into whether intervention during sensitive time periods can reduce long-term disparities in socioeconomic attainment.

More generally, this study suggests a model for deploying molecular genetics to assess heterogeneous treatment effects: We use exogenous variation in the environment and combine it with a well-validated genetic score that displays large and significant effects on the outcome of interest in independent samples. Since heterogeneous treatment effects not only have important implications for social and behavioral research and social policy but also appear to be the norm in response to interventions or to naturally occurring environments (e.g. Angrist \& Krueger, 1999; Heckman, 2001; Manski, 2009; Winship \& Morgan, 1999), our intuition is that genotype may provide the prism to separate out the "white light" of average treatment effects into its constituent "rainbow" of heterogeneous responses by genotype. The present study, we hope, has provided proof of concept for the utility of genotype as a moderator of social inputs that itself may, in turn, generate hidden forms of inequality. 


\section{References}

Almond, Douglas, Chay, Kenneth Y, \& Lee, David S. (2005). The costs of low birth weight. Quarterly Journal of Economics, 120(3), 1031-1083.

Almond, Douglas, \& Mazumder, Bhashkar. (2011). Health capital and the prenatal environment: The effect of Ramadan observance during pregnancy. American Economic Journal: Applied Economics, 3(4), 56-85.

Angrist, Joshua D. (1990). Lifetime earnings and the Vietnam-era draft lottery: Evidence from Social Security administrative records. American Economic Review, 80(5), 313-336.

Angrist, Joshua D. (1993). The effect of veterans benefits on education and earnings. Industrial \& labor relations review, 46(4), 637-652.

Angrist, Joshua D, \& Chen, Stacey H. (2011). Schooling and the Vietnam-Era GI Bill: Evidence from the Draft Lottery. American Economic Journal: Applied Economics, 3(2), 96-118.

Angrist, Joshua D, Chen, Stacey H, \& Frandsen, Brigham R. (2010). Did Vietnam veterans get sicker in the 1990s? The complicated effects of military service on self-reported health. Journal of Public Economics, 94(11), 824-837.

Angrist, Joshua D, Chen, Stacey H, \& Song, Jae. (2011). Long-term consequences of Vietnamera conscription: New estimates using Social Security data. American Economic Review, 101(3), 334-338.

Angrist, Joshua D, \& Krueger, Alan B. (1994). Why do World War II veterans earn more than nonveterans? Journal of Labor Economics, 12(1), 74-97.

Angrist, Joshua D, \& Krueger, Alan B. (1999). Empirical strategies in labor economics. Handbook of Labor Economics, 3, 1277-1366.

Angrist, Joshua D, \& Pischke, Jörn-Steffen. (2008). Mostly Harmless Econometrics: An Empiricist's Companion. Princeton, NJ: Princeton University Press.

Beauchamp, Jonathan P, Cesarini, David, Johannesson, Magnus, van der Loos, Matthijs JHM, Koellinger, Philipp D, Groenen, Patrick JF, . . Christakis, Nicholas A. (2011). Molecular genetics and economics. Journal of Economic Perspectives, 25(4), 57-82.

Belsky, Daniel W, \& Israel, Salomon. (2014). Integrating genetics and social science: Genetic risk scores. Biodemography and Social Biology, 60(2), 137-155.

Benjamin, Daniel J, Cesarini, David, van der Loos, Matthijs JHM, Dawes, Christopher T, Koellinger, Philipp D, Magnusson, Patrik KE, . . Johannesson, Magnus. (2012). The genetic architecture of economic and political preferences. Proceedings of the National Academy of Sciences, 109(21), 8026-8031.

Berger, Mark C, \& Hirsch, Barry T. (1983). The civilian earnings experience of Vietnam-era veterans. Journal of Human Resources, 18(4), 455-479.

Black, Sandra E, Devereux, Paul J, \& Salvanes, Kjell G. (2007). From the cradle to the labor market? The effect of birth weight on adult outcomes. Quarterly Journal of Economics, 122(1), 409-439.

Blackburn, McKinley L, \& Neumark, David. (1993). Omitted-ability bias and the increase in the return to schooling. Journal of Labor Economics, 11(3), 521-544.

Bound, John, \& Turner, Sarah. (2002). Going to war and going to college: Did World War II and the GI Bill increase educational attainment for returning veterans? Journal of Labor Economics, 20(4), 784-815. 
Branigan, Amelia R, McCallum, Kenneth J, \& Freese, Jeremy. (2013). Variation in the heritability of educational attainment: An international meta-analysis. Social Forces, 92(1), 109-140.

Card, David. (1999). The causal effect of education on earnings. Handbook of Labor Economics, 3, 1801-1863.

Card, David (1995). Earnings, schooling, and ability revisited. In Solomon Polachek (Ed.), Research in Labor Economics (Vol. 14, pp. 23-48). Greenwich, CT: JAI Press.

Card, Josefina, J. (1983). Lives After Vietnam. Lexington, MA: Lexington Books.

Carlson, Christopher S, Matise, Tara C, North, Kari E, Haiman, Christopher A, Fesinmeyer, Megan D, Buyske, Steven, . . Ritchie, Marylyn D. (2013). Generalization and dilution of association results from European GWAS in populations of non-European ancestry: The PAGE study. PLoS Biol, 11(9), e1001661.

Cesarini, David, Dawes, Christopher T, Johannesson, Magnus, Lichtenstein, Paul, \& Wallace, Björn. (2009). Genetic variation in preferences for giving and risk taking. Quarterly Journal of Economics, 124(2), 809-842.

Conley, Dalton. (2009). The promise and challenges of incorporating genetic data into longitudinal social science surveys and research. Biodemography and Social Biology, 55(2), 238-251.

Conley, Dalton, \& Bennett, Neil G. (2000). Is biology destiny? Birth weight and life chances. American Sociological Review, 65(3) 458-467.

Conley, Dalton, Domingue, Benjamin W, Cesarini, David, Dawes, Christopher, Rietveld, Cornelius A, \& Boardman, Jason D. (2015). Is the effect of parental education on offspring biased or moderated by genotype? Sociological Science, 2, 82-105.

Conley, Dalton, \& Heerwig, Jennifer. (2012). The long-term effects of military conscription on mortality: Estimates from the Vietnam-era draft lottery. Demography, 49(3), 841-855.

Conley, Dalton, Laidley, Thomas, Belsky, Daniel W, Fletcher, Jason M, Boardman, Jason D, \& Domingue, Benjamin W. (2016). Assortative mating and differential fertility by phenotype and genotype across the 20th century. Proceedings of the National Academy of Sciences, 201523592.

Conti, Gabriella, Heckman, James, \& Urzua, Sergio. (2010). The education-health gradient. American Economic Review, 100(2), 234.

Cutler, David M, \& Lleras-Muney, Adriana. (2010). Understanding differences in health behaviors by education. Journal of Health Economics, 29(1), 1-28.

Deary, Ian J, Strand, Steve, Smith, Pauline, \& Fernandes, Cres. (2007). Intelligence and educational achievement. Intelligence, 35(1), 13-21.

Dobkin, Carlos, \& Shabani, Reza. (2009). The health effects of military service: Evidence from the Vietnam Draft. Economic Inquiry, 47(1), 69-80.

Domingue, Benjamin W, Belsky, Daniel W, Harrati, Amal, Conley, Dalton, Weir, David, \& Boardman, Jason. (2016). Mortality selection in a genetic sample and implications for association studies. BioRxiv, 049635.

Fienberg, Stephen E. (1971). Randomization and social affairs: The 1970 draft lottery. Science, 171(3968), 255-261.

Fletcher, Jason M, \& Conley, Dalton. (2013). The challenge of causal inference in geneenvironment interaction research: Leveraging research designs from the social sciences. American Journal of Public Health, 103(S1), S42-S45. 
Gimbel, Cynthia, \& Booth, Alan. (1996). Who fought in Vietnam? Social Forces, 74(4), 11371157.

Griliches, Zvi. (1979). Sibling models and data in economics: Beginnings of a survey. Journal of Political Economy, 87(5, Part 2), S37-S64.

Griliches, Zvi, \& Mason, William M. (1972). Education, income, and ability. Journal of political Economy, 80(3), S74-S103.

Hearst, Norman, Thomas B. Newman, \& Stephen B. Hulley. (1986). Delayed effects of the military draft on mortality. New England Journal of Medicine, 314(10), 620.

Heckman, James J. (1997). Instrumental variables: A study of implicit behavioral assumptions used in making program evaluations. Journal of Human Resources, 32(3), 441-462.

Heckman, James J. (2001). Micro data, heterogeneity, and the evaluation of public policy: Nobel lecture. Journal of Political Economy, 109(4), 673-748.

Heckman, James J., \& Rubinstein, Yona. (2001). The importance of noncognitive skills: Lessons from the GED testing program. American Economic Review, 91(2), 145-149.

Lemieux, Thomas, \& Card, David. (2001). Education, earnings, and the 'Canadian GI Bill'. Canadian Journal of Economics, 34(2), 313-344.

Lleras-Muney, Adriana. (2005). The relationship between education and adult mortality in the United States. Review of Economic Studies, 72(1), 189-221.

Lucchini, Mario, Della Bella, Sara, \& Pisati, Maurizio. (2013). The weight of the genetic and environmental dimensions in the inter-generational transmission of educational success. European Sociological Review, 29(2), 289-301.

Manski, Charles F. (2009). Identification for Prediction and Decision. Cambridge, MA: Harvard University Press.

Mare, Robert D. (1980). Social background and school continuation decisions. Journal of the American Statistical Association, 75(370), 295-305.

Mason, William M. (1970). On the Socioeconomic Effects of Military Service. Ph.D. dissertation, University of Chicago.

National Center for Veterans Analysis and Statistics. (2015). Quick Facts. Retrieved 6/23/16, 2016, from http://www.va.gov/vetdata/Quick_Facts.asp

Nielsen, François, \& Roos, J. M. (2015). Genetics of educational attainment and the persistence of privilege at the turn of the 21st Century. Social Forces, 94(2), 535-561.

Oi, Walter Y. (1967). The economic cost of the draft. American Economic Review, 57(2), 39-62.

Okbay, Aysu, Beauchamp, Jonathan P, Fontana, Mark Alan, Lee, James J, Pers, Tune H, Rietveld, Cornelius A, . . Meddens, S Fleur W. (2016). Genome-wide association study identifies 74 loci associated with educational attainment. Nature, 533(7604), 539-542.

Price, Alkes L, Patterson, Nick J, Plenge, Robert M, Weinblatt, Michael E, Shadick, Nancy A, \& Reich, David. (2006). Principal components analysis corrects for stratification in genome-wide association studies. Nature Genetics, 38(8), 904-909.

Purcell, Shaun, Neale, Benjamin, Todd-Brown, Kathe, Thomas, Lori, Ferreira, Manuel AR, Bender, David, ... Daly, Mark J. (2007). PLINK: a tool set for whole-genome association and population-based linkage analyses. American Journal of Human Genetics, 81(3), 559-575.

Rietveld, Cornelius A., Medland, Sarah E., Derringer, Jaime, Yang, Jian, Esko, Tõnu, Martin, Nicolas W., . . Agrawal, Arpana. (2013). GWAS of 126,559 individuals identifies genetic variants associated with educational attainment. Science, 340(6139), 1467-1471. 
Rosen, Sherwin, \& Taubman, Paul. (1982). Changes in life-cycle earnings: What do social security data show? Journal of Human Resources, 17(3), 321-338.

Rothbart, George, Sloan, Lee, \& Joyce, Kathleen. (1981). Educational and Work Careers: Men in the Vietnam Generation (Vol. 2). Washington, D.C.: GPO.

Schmitz, Lauren, \& Conley, Dalton. (2015). Modeling gene - environment interactions with quasi - natural experiments. Journal of Personality, advance online publication. DOI: 10.1111/jopy.12227.

Schmitz, Lauren, \& Conley, Dalton. (2016). The long-term consequences of Vietnam-era conscription and genotype on smoking behavior and health. Behavior Genetics, 46(1), 43-58.

Schwartz, Saul. (1986). The relative earnings of Vietnam and Korean-era veterans. Industrial \& Labor Relations Review, 39(4), 564-572.

Stanley, Marcus. (2003). College education and the midcentury GI Bills. Quarterly Journal of Economics, 118(2), 671-708.

Vilhjálmsson, Bjarni J., Yang, Jian, Finucane, Hilary K, Gusev, Alexander, Lindström, Sara, Ripke, Stephan, .. . Do, Ron. (2015). Modeling linkage disequilibrium increases accuracy of polygenic risk scores. American Journal of Human Genetics, 97(4), 576-592.

Visscher, Peter M, Hill, William G, \& Wray, Naomi R. (2008). Heritability in the genomics era-Concepts and misconceptions. Nature Reviews Genetics, 9(4), 255-266.

Winship, Christopher, \& Morgan, Stephen L. (1999). The estimation of causal effects from observational data. Annual Review of Sociology, 659-706.

Wool, Harold. (1968). The Military Specialist: Skilled Manpower for the Armed Forces. Baltimore, MD: Johns Hopkins University Press. 